\title{
The Roles of Depth and Breadth of Vocabulary Knowledge in EFL Reading Performance
}

\author{
Zhifa Shen \\ School of Foreign Languages \\ Zhejiang Gongshang University \\ Hangzhou 310018, China \\ E-mail: 1977shenzf@sina.com
}

\begin{abstract}
Vocabulary knowledge plays a very important role in reading tests and reading research has consistently found a word knowledge factor on which vocabulary tests load highly. Tests of vocabulary are highly predictive of performance on tests of reading comprehension. The present paper intends to review in detail the relationships between the breadth and depth of vocabulary knowledge and EFL reading comprehension.
\end{abstract}

Keywords: Depth of vocabulary knowledge, Breadth of vocabulary knowledge, Reading performance

\section{Introduction}

In recent years, second language vocabulary acquisition has been an increasingly interesting topic of discussion for researches, teachers, curriculum designers, theorists and others involved in second language learning. All sees vocabulary as being a very important element in language. Interest in the relationship between vocabulary and reading comprehension has a long history in the research of ESL/EFL reading. Observing the performance of ESL/EFL readers, confronted with unknown vocabulary, researchers have noted the important role of vocabulary as a predictor of overall reading ability (Nation, 1990). In fact, second/foreign language readers often cite lack of adequate vocabulary as one of the obstacles to text comprehension.

Vocabulary load is the most significant predictor of text difficulty. Haynes and Baker (1993) also came to the conclusion that the most significant handicap for L2 readers is not lack of reading strategies but insufficient vocabulary in English. What these studies indicate is that the threshold for reading comprehension is, to a large extent, lexical. Lexical problems will, therefore, hinder successful comprehension. The present paper intends to review the relationships between the breadth and depth of vocabulary knowledge and EFL reading comprehension.

\section{Four perspectives on the vocabulary-reading connection}

The relationship between vocabulary knowledge and reading comprehension is complex and dynamic. Researchers have suggested several models to describe the relationship between vocabulary knowledge and reading comprehension. Anderson and Freebody (1981) offered three hypotheses labeled "instrumentalist", "aptitude" and "knowledge".

The instrumentalist view sees vocabulary knowledge as being a major prerequisite and causative factor in comprehension. Good vocabulary knowledge enables good comprehension. The aptitude view sees vocabulary knowledge as one of many outcomes of having a good brain. Good reading comprehension is also one of these outcomes. Other outcomes might include skill at non-verbal puzzles and the ability to understand oral explanation. The knowledge view sees vocabulary as an indicator of good world knowledge. This world knowledge supports reading comprehension because the reader must bring as much information to the text as the reader expects to get from it. It is difficult to read about astrophysics if you know nothing about it. Mezynski (1983) suggested a fourth "access" hypothesis. The access view of the relationship between vocabulary knowledge and reading comprehension, like the instrumentalist view, sees vocabulary as having a causal relationship with comprehension provided that the vocabulary can be easily accessed. Access can be improved through practice. This access can involve several factors including fluency of lexical access, speed of coping with affixed forms, and speed of word recognition.

For EFL/ESL learners, the relationship between vocabulary knowledge and reading comprehension are even more complicated. These complications can arise from the learners being able to read in their first language and the common situation of beginning to read the target language with virtually no vocabulary knowledge in the target language. That indicates for EFL/ESL learners the vocabulary knowledge plays a more important role in reading comprehension. 


\section{Defining vocabulary knowledge}

In recent decades, in order to define what it means to know a word, second language (L2) vocabulary researchers have proposed various but complementary frameworks. Most researchers agree that lexical knowledge is not an all-or-nothing phenomenon, but involves degrees of knowledge. They suggest it should be constructed as a continuum, or continua, consisting of several levels and dimensions of knowledge.

Much of what is written on word knowledge goes back to the well-known vocabulary knowledge framework of Richards (1976). He identified seven aspects of word knowledge (e.g. syntactic behavior, associations, semantic value, different meanings, underlying form and derivations). Nation (1990) distinguished eight types of word knowledge (e.g. form, grammatical pattern, meaning, function, relation with other words), which were specified both for receptive and productive knowledge. Chapelle (1998) argued that a trait definition of vocabulary should contain four dimensions: (a) vocabulary size, (b) knowledge of word characteristics, (c) lexicon organization, and (d) processes of lexical access. Henriksen (1999) proposed three separate but related vocabulary dimensions: (a) a "partial-precise knowledge" dimension, (b) a "depth of knowledge" dimension, and (c) a "receptive-productive" dimension. Qian's (2002) recent framework, developed on the collective strength of earlier models of vocabulary knowledge proposed that vocabulary knowledge comprises four intrinsically connected dimensions: (a)vocabulary size, (b) depth of vocabulary knowledge, (c) lexical organization, and (d) automaticity of receptive-productive knowledge. The importance of various factors in these dimensions will vary according to the specific purpose of language use.

In all the frameworks reviewed, there is a clear consensus that vocabulary knowledge should at least comprise two dimensions, which are vocabulary breadth, or size, and depth, or quality, of vocabulary knowledge. Vocabulary breadth refers to the number of words the meaning of which a learner has at least some superficial knowledge. Depth of vocabulary knowledge is defined as a learner's level knowledge of various aspects of a given word, or how well the learner knows this word.

\section{Research on breath of vocabulary knowledge and reading comprehension}

Breath of vocabulary knowledge is defined as the number of words that a person knows. With native speakers, the objective of studies in this area has been to measure the number of words that they know in some absolute sense, whereas with second language learners the aim is often more narrowly defined in terms of their knowledge of items in a specified list of relatively high frequency words, such as the General Service List.

Vocabulary size tests that are used for proficiency or placement purposes should include the broadest possible range of word families. An estimation of total vocabulary size can be attained in two ways. The first is based on sampling from a dictionary, and the second is based on corpus-derived lists of word families grouped by frequency. The dictionary sampling method involves selecting a dictionary that contains the number of word families that learners are expected to know, then testing a selection of those words. The problem with this method is that higher frequency words tend to have longer entries, and are thus more likely to end up on the test, which may skew the results.

The second method to estimate vocabulary size is to select word families according to their frequency in a corpus. Usually, these word families are grouped together into the first 1,000 most frequent words, the second 1,000 most frequent words, and so on. This kind of test has generally been used only with people with low English vocabularies, namely non-native speakers of English (Nation, 1990).

There are currently two widely used vocabulary size tests available, the Eurocentres Vocabulary Size Test 10KA (EVST; Meara and Jones, 1990), the Vocabulary Levels Test (VLT; Nation, 1983, 1990). They are well documented in the literature. More specifically, there is research evidence available concerning their validity as assessment procedures for their intended purpose. They also represent innovations in vocabulary assessment and serve to highlight interesting issues in the test design.

Laufer (1996) and Qian's (1999, 2002, 2004)research on the relationship between the breath of vocabulary knowledge and reading comprehension has produced results indicating relatively high correlation, ranging from 0.50 to 0.78 , between the two factors. Meara (1996) calls VLT the "nearest thing we have to a standard test in vocabulary". In the recent research about the relation between the breadth of vocabulary knowledge and reading comprehension in Chinese situation the correlation ranges widely. In Yang and Deng's (1996) research, the correlation was very high ( $\mathrm{r}=0.89$ $\mathrm{P}<0.01)$. In Li's (2003) research, it was moderate $(\mathrm{r}=0.69 \mathrm{P}<0.01)$. But Lu (2004) found a low correlation between the two factors $(\mathrm{r}=0.321 \mathrm{p}<0.01)$.

\section{Research on depth of vocabulary knowledge and reading comprehension}

Depth of knowledge focuses on the idea that for useful higher-frequency words learners need to have more than just a superficial understanding of the meaning. According to Qian (1999), the depth dimension should cover such components as pronunciation, spelling, meaning, register, frequency, and morphological, syntactic, and collocational properties. There are two main approaches for measuring depth of vocabulary knowledge: a developmental approach and a dimensional approach (Read, 1997). The developmental approach uses scales to describe the stages of acquisition 
of a word. One scale that has received some attention is the Vocabulary Knowledge Scale, which has five levels.

The dimensional approach, on the other hand, describes the level of mastery of the various component types of word knowledge. This approach has its roots in a seminal paper by Richards (1976) which set out a number of competencies necessary for mastery of a word. Later scholars have taken up the idea, suggesting their own lists of word knowledge types. Schmitt (1998) states it is in a research context that the dimensional approach may prove to be of more value. Measuring several vocabulary knowledge types would be time-consuming and would severely limit the number of words that could be studied. However, many researchers believe that such research has several advantages, making it well worth the effort. Schmitt and Meara(1997) examined how two types of word knowledge, i.e. word association and verbal suffix changed over time both receptively and productively.

Qian $(1999,2002,2004)$ used the depth-of-vocabulary-knowledge (DVK) measure in his investigation of the relationship between L2 vocabulary knowledge and reading comprehension ability. DVK measure was intended to contribute to inferences about the test-taker's depth of receptive English vocabulary knowledge by measuring three vocabulary elements: synonymy, polysemy, and collocation. He showed that this DVK measure accounted for a significant amount of the variance in the reading scores beyond what was predicted by a vocabulary breadth test. However, he suggested caution should be exercised in generalizing the findings from the study because the concept of depth of vocabulary knowledge was only partially operationalized. However, In China LI (2003) showed in his study that the correlation between the depth of vocabulary (the preciseness of the word definition; the ability to choose the meaning of words according to the context; the syntactic characteristic of the vocabulary) and reading comprehension was lower than that of the breath of vocabulary and reading comprehension. He also made a tentative conclusion that polysemy might contribute little to reading comprehension.

\section{Conclusion}

Vocabulary knowledge plays a very important role in reading tests and reading research has consistently found a word knowledge factor on which vocabulary tests load highly. Tests of vocabulary are highly predictive of performance on tests of reading comprehension. A lot of researches show that depth of vocabulary knowledge, breadth of vocabulary knowledge and reading comprehension are highly, and positively, correlated. Depth of vocabulary knowledge made a significant, and unique, contribution to the prediction of scores on reading comprehension beyond the prediction provided by the breadth of vocabulary knowledge. However, in Chinese situation, the correlation among the breadth and depth of vocabulary knowledge and reading comprehension ranges widely, which needs to be explored further with empirical evidences.

\section{References}

Alderson, R.C. and Freedy, P. (1981). Vocabulary Knowledge. In Guthrie, J.T. (Ed.), Comprehension and teaching: Research reviews. Newark, DE: International Reading Association, 77-117.

Chapelle, C.A. (1998). Construct definition and validity inquiry in SLA research. In Bachman, L.F. and Cohen, A.D. (Eds.), Interfaces between second language acquisition and language testing research. Cambridge: Cambridge University Press, 32-70.

Henriksen, B. (1999). Three dimensions of vocabulary development. Studies in Second Language Acquisition 21, 303-317.

Li Jun.(2003). On the Relationship Between the Breadth and the Depth of Vocabulary and Reading Comprehension. Foreign Language Education(2),21-24.

Lu Changhong. (2004). Vocabulary size and its influence on English achievement as well as its relationship to depth of lexical knowledge. Foreign Language Teaching and Research(2),116-123.

Meara, P. and Jones, G. (1990). Eurocentrtres Vocabulary Size Test, Version E1.1/K10. Zurich: Eurocentrtres Learning Service.

Mezynski, K. (1983). Issues concerning the acquisition of knowledge: effects of vocabulary training on reading comprehension. Review of educational research 2, 253-279.

Nation, I.S.P. (1990). Teaching and learning vocabulary. New York: Newbury House.

Qian, D.D. (2002). Investigating the relationship between vocabulary knowledge and academic reading performance: an assessment perspective. Language Learning 52(3), 513-536.

Richards, J.C. (1976). The role of vocabulary teaching. TESOL Quarterly 10, 77-89.

Schmitt, N. (1998). Tracking the incremental acquisition of second language vocabulary: a longitudinal study. Language Learning 48(2), 281-317. 